\title{
Migration of Erythroblastic Islands toward the Sinusoid as Erythroid Maturation Proceeds in Rat Bone Marrow
}

\author{
Toshifumi YOKOYAMA ${ }^{1)}$, Takao ETOH ${ }^{2)}$, Hiroshi KITAGAWA ${ }^{1) *}$, Shinji TSUKAHARA ${ }^{1)}$ and Yasuyuki KANNAN ${ }^{1)}$ \\ ${ }^{1)}$ Departments of Life Science and ${ }^{2)}$ Animal Science, Graduate School of Science and Technology, Kobe University, Kobe 657-8501, \\ Japan
}

(Received 22 August 2002/Accepted 20 December 2002)

\begin{abstract}
It has been hitherto considered that mature erythroblasts migrate toward the sinusoid along the cytoplasmic processes of macrophages of erythroblastic islands in bone marrow. Our previous report, however, has demonstrated the morphological features of a mature erythroblastic island passing through the sinusoidal endothelium. In this study, the possibility of migration of erythroblastic islands toward the sinusoid was examined in rat bone marrow by light microscopical histoplanimetry. As a result, the more mature erythroblasts were not regularly arranged in the peripheral direction of the erythroblastic islands. Immature erythroblasts wer e populated more in the erythroblastic islands away from the sinusoid than in those islands neighboring the sinusoid, whereas mature erythroblasts were more in erythroblastic islands neighboring the sinusoid. These findings suggest that the formation of erythroblastic islands occurs in a region away from the sinusoid, and that erythroblastic islands migrate towards the sinusoids as erythroid maturation proceeds. KEY WORDS: bone marrow, erythroblastic island, erythropoiesis, migration.
\end{abstract}

J. Vet. Med. Sci. 65(4): 449-452, 2003

In the process of erythropoiesis in bone marrow, erythroid cells are organized into small anatomical units called erythroblastic islands [4], which are formed by colony-forming unit-erythroid (CFU-E) [11]. In general, CFU$\mathrm{E}$ that is more sensitive to erythropoietin, differentiates into erythroid series [6]. Erythroblasts at various maturation stages are mixed in an erythroblastic island in vivo [3]. It is considered that the mature erythroblasts move along the cytoplasmic extension of a central macrophage toward the sinusoid [4]. However, little evidence has been reported about the spatial relationship between erythroblasts at each maturation stage and the central macrophage within an erythroblastic island.

Several lines of evidence have proposed that solitary matured erythroid cells migrate into the blood stream through a transient migration pore of sinusoidal endothelium in bone marrow [1, 5, 9]. However, based on our previous report, reticulocytes are transported to the sinusoidal lumen by a central macrophage [15]. Taken together, it is controversial whether erythroblastic islands themselves migrate toward the sinusoid in the parenchyma of bone marrow. Therefore, the present study was designed to examine the possibility of migration of erythroblastic islands, and to determine the spatial relationships among erythroblasts at various maturation stages in the erythroblastic islands by quantitative light microscopy and qualitative electron microscopy in rat bone marrow.

\section{MATERIALS AND METHODS}

Animals: Five male Wistar rats aged 5-6 weeks (SLC,

\footnotetext{
* Correspondence to: Kitagawa, H., Division of Relational Biosystems, Department of Life Science, Graduate School of Science and Technology, Kobe University, Kobe 657-8501, Japan.
}

Japan) were used according to the guidelines for the care and use of experimental animals, in Rokkodai Campus, Kobe University. The animals had free access to food and water. The animal facility was maintained under conditions of a $12 \mathrm{hr}$ light/dark cycle at $21 \pm 1^{\circ} \mathrm{C}$ and $50-60 \%$ humidity. No sign of hematological disorder was confirmed by clinical and pathological examinations in all animals. Serum erythropoietin concentrations were at the normal level $(20 \mathrm{mIU} / \mathrm{ml})$.

Tissue preparation: Immediately after euthanasia by inhalation of diethyl ether, animals were perfused with $2.5 \%$ glutaraldehyde- $2 \%$ paraformaldehyde in $0.1 \mathrm{M}$ phosphate buffer (PB, pH 7.4). Bone marrow was transversely cut into small pieces, and immersion-fixed in the same fixative for $24 \mathrm{hr}$ at $4^{\circ} \mathrm{C}$. After postfixation with $1 \% \mathrm{OsO}_{4}$ in $0.1 \mathrm{M} \mathrm{PB}$ for $1.5 \mathrm{hr}$ at room temperature, the small specimens were embedded in an epoxy resin (Quetol 812 mixture).

Light microscopical histoplanimetry: Semithin sections of $1 \mu \mathrm{m}$-thickness were cut along the square planes with the radial arrays of sinusoids by using an ultramicrotome (Sorvall MT-1, U.S.A.). The sections were stained with $0.05 \%$ toluidine blue in $0.01 \mathrm{M} \mathrm{PB}(\mathrm{pH} 7.4)$.

Appearance frequencies of erythroblasts of each stage, proerythroblasts, basophilic erythroblasts, polychromatophilic erythroblasts, and acidophilic erythroblasts were measured on the centrally sectioned erythroblastic islands and the peripherally sectioned islands. Eighty erythroblastic islands were randomly sampled from the parenchyma in the sections from each animal.

Regional differences in the components of erythroblastic islands were investigated by comparing erythroid series of 40 erythroblastic islands attached to the sinusoidal endothelium (neighboring the sinusoid) with that of 40 erythroblastic islands away from the sinusoid. Unpaired $t$ test was employed for detection of statistical significances 
with the value of $p<0.05$.

Electron microscopy: Ultrathin sections contrasted with both uranyl acetate and lead citrate were observed by using a transmission electron microscope (Hitachi H-7100, Japan) at an accelerating voltage of $75 \mathrm{kV}$.

\section{RESULTS}

Qualitative observation: Erythroblastic islands consisted of erythroid cells of various maturation stages. Erythroblastic constitution was not uniform in each erythroblastic island. Namely, erythroblastic islands with only immature erythroid cells (proerythroblasts and basophilic erythroblasts) or erythroblastic islands with only mature erythroid cells (polychromatophilic erythroblasts, acidophilic erythroblasts and reticulocytes) were often observed. In the parenchyma beneath the sinusoidal endothelium, many erythroblastic islands were predominantly composed of mature erythroblasts and reticulocytes, whereas proerythroblasts seldom appeared in these islands (Figs. 1, 2). Solitary reticulocytes were also found beneath the sinusoidal endothelium. The egress of solitary erythrocytes through the sinusoidal endothelium from parenchyma to the sinusoid lumen was occasionally observed (Fig. 3).

Quantitative analyses: In every erythroblastic island, the predominant component was polychromatophilic erythroblast, and the second was the basophilic erythroblast. Other types of erythroblasts rarely appeared in the island. No differences were seen between the appearance frequencies of each type of erythroblast in the central portion and those in the peripheral portion of an erythroblastic island (Table 1).

No regional differences were measured between the numbers of polychromatophilic or basophilic erythroblasts

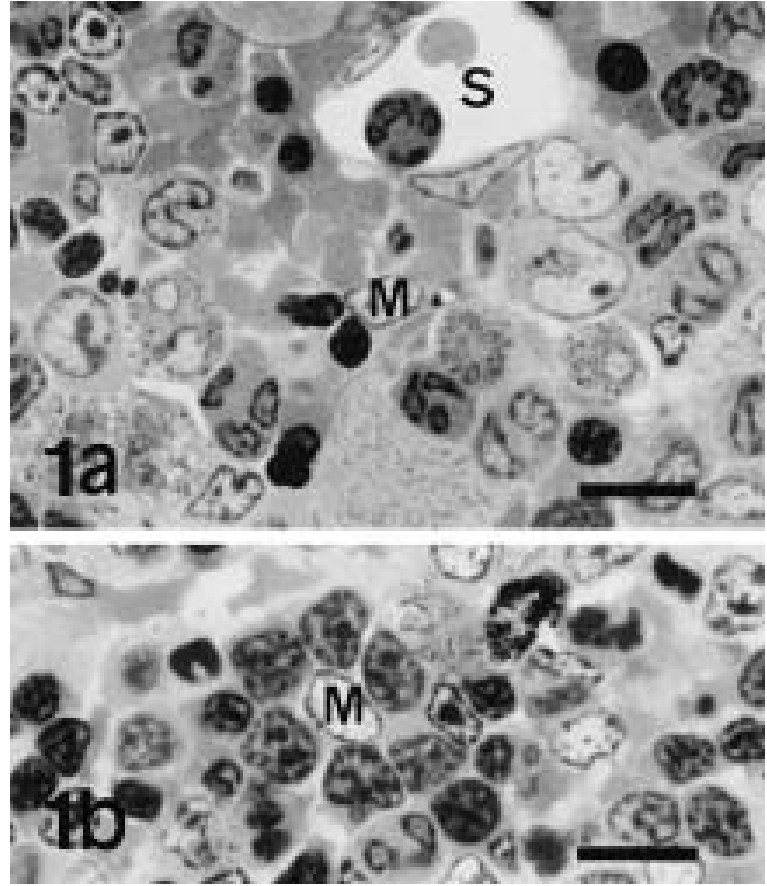

Fig. 1. Light micrographs of a matured erythroblastic island and clustered reticulocytes beneath the sinusoid (S) (a) and of an immature erythroblastic island (b). $\mathrm{M}$, central macrophage. Bar $=10 \mu \mathrm{m}$

in an erythroblastic island neighboring the sinusoid and that away from the sinusoid. The appearance of proerythroblasts, however, was significantly more frequent in erythroblastic islands away from the sinusoid than in those
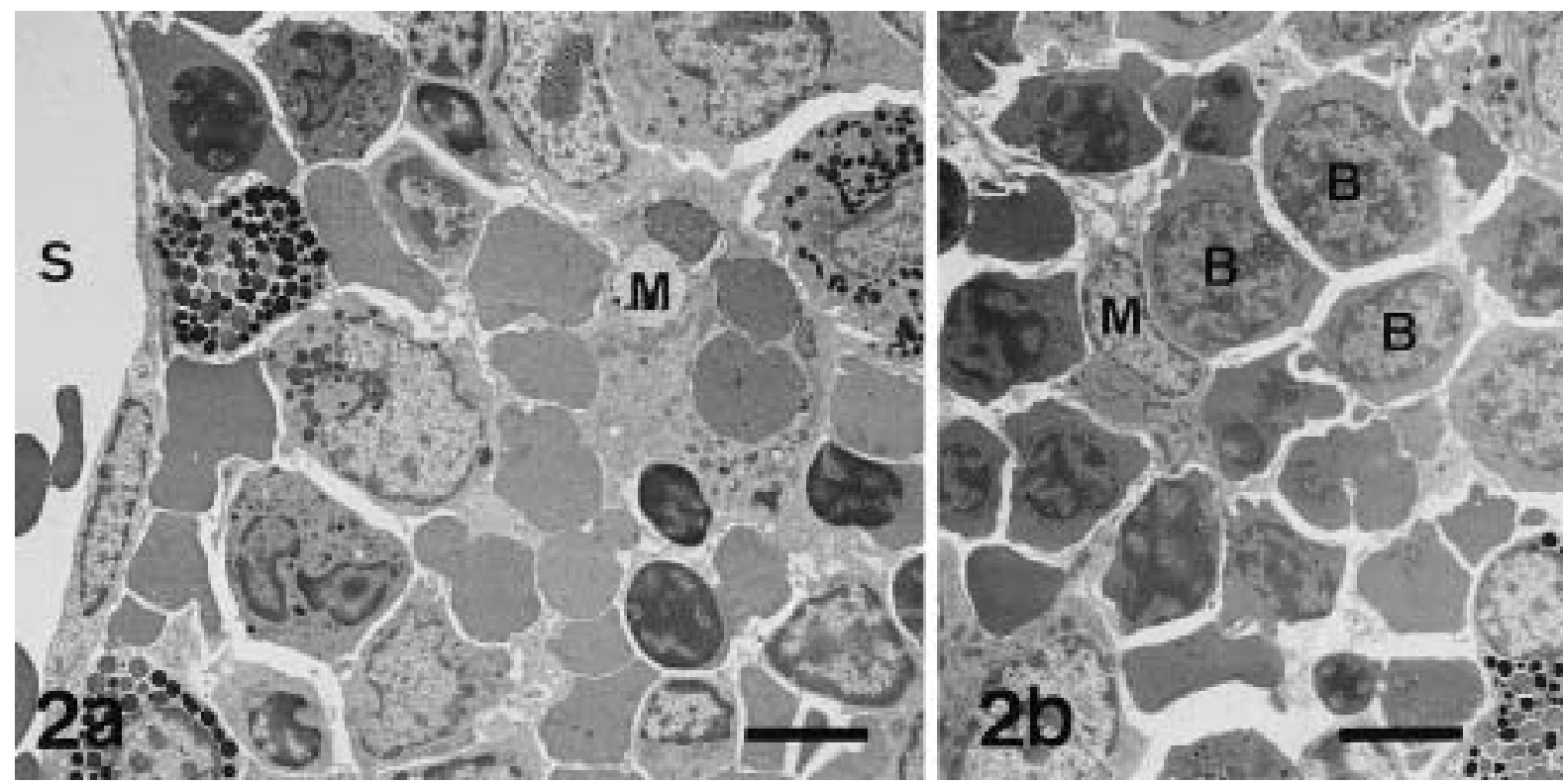

Fig. 2. An electron micrograph of a matured erythroblastic island and clustered reticulocytes beneath the sinusoid (S) (a) and of an immature erythroblastic island (b). M, central macrophage; B, basophilic erythroblast. $\mathrm{Bar}=5 \mu \mathrm{m}$. 


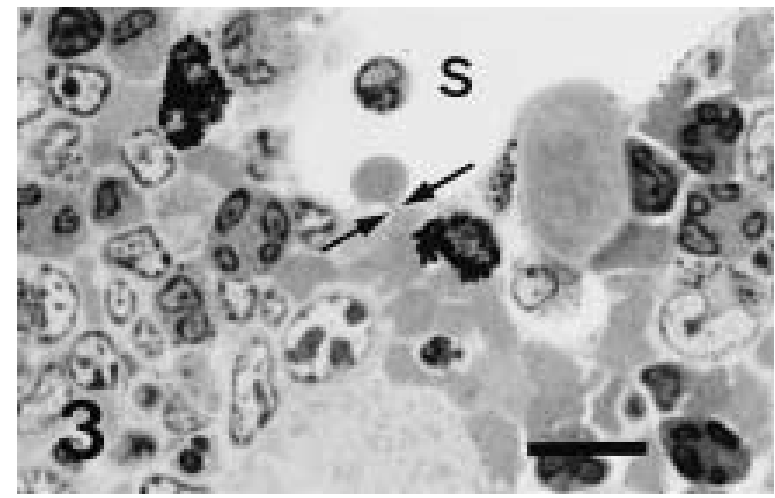

Fig. 3. Egress of solitary erythrocyte (between arrows) through the sinusoidal endothelium into the sinusoidal lumen $(\mathrm{S})$. Bar $=10 \mu \mathrm{m}$.

Table 1. Spatial relationship of erythroblasts to central macrophages in an erythroblastic island of rat femoral bone marrow

\begin{tabular}{lcc}
\hline Erythroblasts & Periphery of EI & Center of EI \\
\hline Pro-EB & $1.9 \pm 1.8^{*}$ & $1.0 \pm 1.3$ \\
Baso-EB & $8.6 \pm 3.7$ & $11.0 \pm 14.6$ \\
Poly-EB & $88.1 \pm 6.1$ & $87.8 \pm 19.9$ \\
Acid-EB & $1.4 \pm 1.4$ & $1.8 \pm 0.8$ \\
\hline
\end{tabular}

* Appearance ratio of erythroblasts in an erythroblastic island (\%) \pm SD; EI, erythroblastic island; Pro-EB, proerythroblast; Baso-EB, basophilic erythroblast; Poly-EB, polychromatophilic erythroblast; and Acid-EB, acidophilic erythroblast.

Table 2. Regional differences of erythroblastic islands in parenchyma of rat bone marrow

\begin{tabular}{lll}
\hline Erythroblasts & $\begin{array}{l}\text { Neighboring } \\
\text { the sinusoid }\end{array}$ & $\begin{array}{c}\text { Away from } \\
\text { the sinusoid }\end{array}$ \\
\hline Pro-EB & $0.02 \pm 0.02^{\text {a)* }}$ & $0.24 \pm 0.20^{\text {a) }}$ \\
Baso-EB & $0.53 \pm 0.43$ & $0.77 \pm 0.53$ \\
Poly-EB & $5.46 \pm 0.97$ & $5.29 \pm 0.85$ \\
Acid-EB & $0.19 \pm 0.15^{\text {b) }}$ & $0.03 \pm 0.03^{\text {b) }}$ \\
\hline
\end{tabular}

* Mean number of erythroid cells per an erythroblastic island $\pm \mathrm{SD}$; Pro-EB, proerythroblast; Baso-EB, basophilic erythroblast; Poly-EB, polychromatophilic erythroblast; and Acid-EB, acidophilic erythroblast; a), b), $p<0.05$.

neighboring the sinusoid $(p<0.05)$. On the other hand, acidophilic erythroblasts were more frequently found in the erythroblastic islands neighboring the sinusoid than in those away from the sinusoid $(p<0.05)$ (Table 2$)$.

\section{DISCUSSION}

The present histoplanimetry showed similar erythroid populations in the central portion and the peripheral portion of erythroblastic islands. If more mature erythroblasts migrate toward the sinusoid, the greater numbers of mature erythroblasts should be found in the peripheral portion of erythroblastic islands than in the central portion. Thus, the present results do not support the previous report, which suggested that the matured erythroblasts move toward the sinusoid along the cytoplasmic processes of central macrophages [4].

CFU-E adheres to the macrophage and forms an erythroblastic island [11]. Heretofore, the formation site of erythroblastic islands in parenchyma of bone marrow was unclear. In the present histoplanimetry, the early stage erythroblasts were found more frequent in erythroblastic islands away from the sinusoid, whereas the late stage erythroblasts in those neighboring the sinusoids. This finding suggests that the formation of erythroblastic islands occurs in a region away from the sinusoid, and that the erythroblastic islands migrate toward the sinusoids as erythroid maturation proceeds.

In this study, the transendothelial egress of solitary reticulocytes was confirmed, in addition to the egress of erythroblastic islands accompanied with reticulocytes [15]. The transportation of solitary matured erythroid cells into the blood stream was predominant than the other one. In hepatic erythropoiesis, after release of reticulocytes, the central macrophages of erythroblastic islands migrate into the sinusoids and the cells are phagocytized by the sinusoidal scavenger macrophages [12]. Taking this phenomenon in consideration, the central macrophages might migrate into the sinusoids after completion of erythroid proliferation in erythroblastic islands of bone marrow.

Egress of reticulocytes through the endothelial pores requires higher pressure in the direction of the sinusoids, because the membrane of the reticulocyte is more rigid than that of the mature erythrocyte [14]. Since the pressure within the sinusoids is pulsatile, the pressure sufficient to cause egress may be transient [1]. The egress of reticulocytes is accelerated by serum erythropoietin [2]. However, the detailed mechanisms of mature erythroid cells transferring into the blood stream have not yet been clarified. On the other hand, in the small intestine $[7,10,13]$ and the epidermis [8], the pressure produced by cell division of immature cells drives the divided cells in a particular direction.

Therefore, a synergistic effect of blood pressure in the sinusoids and pressure caused by cell proliferation of immature erythroid cells might drive the erythroblastic islands toward the sinusoid (Fig. 4).

ACKNOWLEDGEMENT. This work was financially supported in part by a Grant-in-Aid for Scientific Research (no. 13660298) from the Japan Society for the Promotion of Science.

\section{REFERENCES}

1. Abboud, C. N. and Lichtman, M. A. 1995. Structure of the marrow. pp. 25-38. In: Williams Hematology, 5th ed. (Beutler, 


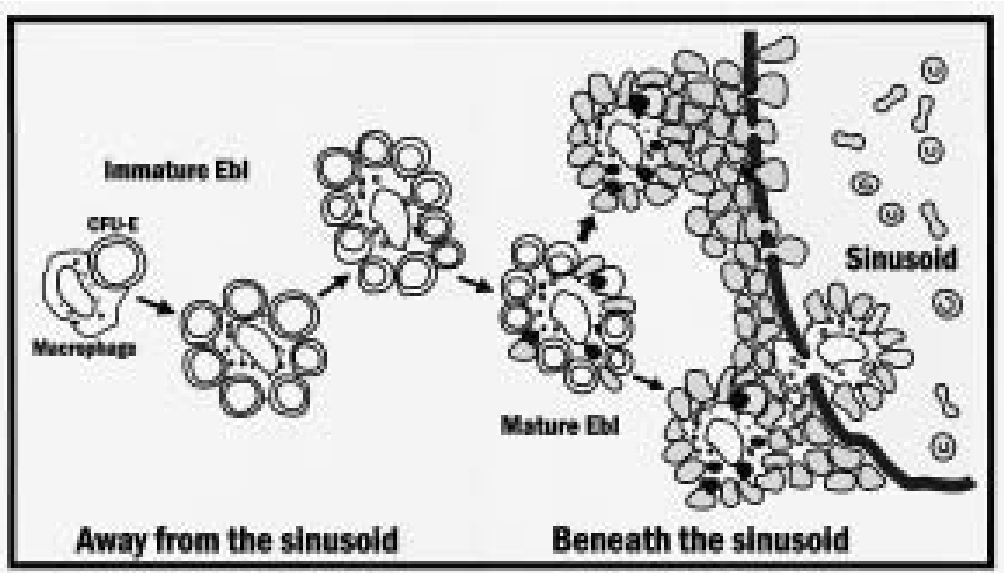

Fig.4. Two transportation patterns of matured erythroid cells into the blood stream in rat bone marrow. EbI, erythroblastic island.

E., Lichtman, M. A. and Coller, B. S. eds.), McGraw-Hill Inc., New York.

2. Aoki, M. and Tavassoli, M. 1981. Dynamics of red cell egress from bone marrow after blood letting. Br. J. Haematol. 49: 337-347.

3. Bessis, M., Mize, C. and Prenant, M. 1978. Erythropoiesis: comparison of in vivo and in vitro amplification. Blood Cells 4 : $155-174$.

4. Bull, B. S. and Breton-Gorius, J. 1995. Morphology of the erythron. pp. 349-363. In: Williams Hematology, 5th ed. (Beutler, E., Lichtman, M. A. and Coller, B. S. eds.), McGrawHill Inc., New York

5. De Bruyn, P. P., Michelson, S. and Thomas, T. B. 1971. The migration of blood cells of the bone marrow through the sinusoidal wall. J. Morphol. 133: 417-437.

6. Erslev, A. J. and Beutler, E. B. 1995. Production and destruction of erythrocytes. pp. 425-441. In: Williams Hematology, 5th ed. (Beutler, E., Lichtman, M. A. and Coller, B. S. eds.), McGraw-Hill Inc., New York.

7. Loeffler, M., Stein, R., Wichmann, H. E., Potten, C. S., Kaur, P. and Chwalinski, S. 1986. Intestinal cell proliferation. I. A comprehensive model of steady-state proliferation in the crypt. Cell Tissue Kinet. 19: 627-645.

8. Monteiro-Riviere, N. A., Stinson, A. W. and Calhoun, H. L.
1993. Integument. pp. 285-312. In: Textbook of Veterinary Histology, 4th ed. (Dellmann, H. D. ed.), Lea \& Febiger, Philadelphia.

9. Muto, M. 1976. A scanning and transmission electron microscopic study on rat bone marrow sinuses and transmural migration of blood cells. Arch. Histol. Jpn. 39: 51-66.

10. Potten, C. S. and Loeffler, M. 1987. A comprehensive model of the crypts of the small intestine of the mouse provides insight into the mechanisms of cell migration and the proliferation hierarchy. J. Theor. Biol. 127: 381-391.

11. Sadahira, Y. and Mori, M. 1999. Role of the macrophage in erythropoiesis. Pathol. Int. 49: 841-848.

12. Sasaki, K. and Iwatsuki, H. 1997. Origin and fate of the central macrophages of erythroblastic islands in the fetal and neonatal mouse liver. Microsc. Res. Tech. 39: 398-405.

13. Takeuchi, T., Kitagawa, H., Imagawa, T. and Uehara, M. 1998. Proliferation and cellular kinetics of villous epithelial cells and M cells in the chicken caecum. J. Anat. 193: 233-239.

14. Waugh, R. E. 1991. Reticulocyte rigidity and passage through endothelial-like pores. Blood 78: 3037-3042.

15. Yokoyama, T., Kitagawa, H., Takeuchi, T., Tsukahara, S. and Kannan, Y. 2002. No apoptotic cell death of erythroid cells of erythroblastic islands in bone marrow of healthy rats. $J$. Vet. Med. Sci. 64: 913-919. 